\title{
Starvation stress modulates the expression of the Aspergillus nidulans brlA regulatory gene
}

\author{
Isaac Skromne, Olivia Sánchez and Jesús Aguirre \\ Author for correspondence: Jesús Aguirre. Tel: +525622 5651. Fax: + 5256225630 . \\ e-mail: jaguirre@ifcsun1.ifisiol.unam.mx
}

Instituto de Fisiología Celular, Universidad Nacional Autónoma de México, Apartado postal 70242, 04510 Mexico, DF
Expression of the Aspergillus nidulans brIA gene plays a fundamental role in the switch from vegetative growth to asexual reproduction. Using a mediashifting protocol to induce submerged sporulation and brIA-lacz as an expression marker, it was shown that carbon and nitrogen starvation stress induced briA transcription to different degrees. Glucose starvation induced brIA rapidly to high levels and resulted in spore formation on reduced conidiophores, whereas nitrogen starvation induced brlA gradually to lower levels and sporulation occurred to a lesser extent but from more complex conidiophores. $\beta$-Galactosidase activity paralleled $b r I A \alpha$ and $b r I A \beta$ mRNA. No clear qualitative differences between the two brIA transcripts were found in these starvation conditions, suggesting that the different patterns of sporulation could be explained by quantitative expression differences. Since brIA mRNA did not accumulate in the presence of a high glucose concentration, we investigated the role of other carbon sources on brlA expression. Nonrepressing carbon sources such as glycerol, acetate and arabinose were as effective as glucose in preventing brIA mRNA accumulation, suggesting that the glucose effects on brIA expression could be explained as a response to nutrient starvation, rather than by carbon catabolite repression. Despite similar low levels of briA transcripts being detected during growth in glucose or non-repressing carbon sources, conidiophores were formed only in medium containing glycerol, acetate or arabinose. When mycelia were not shifted to starvation conditions, sporulation was not observed in standard minimal medium even after glucose was exhausted, unless the medium was buffered. This and other results suggest that strong deviation from external neutral pH partially prevented full induction and/or function of brIA.

Keywords: Aspergillus nidulans, $\operatorname{br} l A$, starvation stress, glucose regulation, submerged sporulation

\section{INTRODUCTION}

Development in many micro-organisms has often been shown to be induced by nutrient limitation and other conditions which have a detrimental effect on growth, but very little is known about how these environmental signals lead to development (for a discussion see Hansberg \& Aguirre, 1990; Strauch \& Hoch, 1992). Asexual reproduction (conidiation) of the Ascomycete fungus Aspergillus nidulans is an excellent experimental system to study these signals, since the different conditions able to induce sporulation will converge upon expression of the brl $A$ (Bristle) gene. This is an early regulatory gene involved in the formation of the conidiophores of $A$. nidulans. These multicellular, spore-producing structures are composed of a basal foot cell, an aerial stalk ending in a multinucleate globose vesicle, a layer of uninucleate primary sterigmata or metulae, and a layer of uninucleate secondary sterigmata or phialides, from which spores are produced by repeated division (Clutterbuck, 1969; Oliver, 1972; Mims et al., 1988). Mutants in $b r l A$ form aerial stalks that fail to differentiate vesicles, metulae, phialides or spores (Clutterbuck, 1969). They also fail to express many genes associated with later stages of conidiophore development (Zimmermann et al., 1980; Boylan et al., 1987; Adams et al., 1988; Mirabito et al., 1989; Clutterbuck, 1990; Stringer et al., 1991; Timberlake, 1991).

The $\operatorname{brl} A$ gene encodes two mRNAs, designated $b r l A \alpha$ and $\operatorname{brl} A \beta$. The $b r l A \beta$ mRNA encodes a polypeptide 
which is a putative Zinc-finger transcription factor identical to $b r l A \alpha$, except that 23 additional amino acids are present at the amino terminus (Adams et al., 1988; Prade \& Timberlake, 1993). brl $A \alpha / \beta$ transcripts are present at barely detectable levels in hyphae, and begin to accumulate about $5 \mathrm{~h}$ after induction of development by exposure to air (Boylan et al., 1987; Prade \& Timberlake, 1993), primarily in conidiophore vesicles, metulae and phialides (Aguirre et al., 1990). Under conditions where sporulation does not normally occur, expression of either brlA $\alpha$ or $b r l A \beta$ from the strongly inducible alc $A$ promoter results in spore production from hyphal tips (Adams et al., 1988; Han et al., 1993).

Since expression of $b r l A$ leads to sporulation, it is important to understand how this gene is regulated. In $A$. nidulans the ability to conidiate, and therefore to express $\operatorname{brl} A$, is not reached until a certain amount of mycelial growth is completed, a phenomenon described as competence (Axelrod et al., 1973). Competent mycelia, however, will not differentiate until sporulation is induced by exposure to air (Axelrod et al., 1973; Champe \& Simon, 1992 ), or as shown in this paper, by nutrient limitation.

It has been reported that other $A$. nidulans developmental regulatory genes (such as $\operatorname{stu} A, \operatorname{med} A$ and $a b a A ;$ Mirabito et al., 1989) control the pattern of expression of the $b r l A$ gene, including $b r l A$ itself (Aguirre, 1993). However, half of the total induction of $\mathrm{brl} A$ transcription is $\mathrm{brlA}$ independent (Aguirre, 1993), and nothing is known about the signals that initiate $b r l A$ expression. The study of such signals has been limited by the fact that sporulation in $A$. nidulans is typically induced by exposure to air in solid media, a condition where environmental factors such as the nutritional status of the cells are difficult to evaluate and manipulate.

In this paper, we show that the $\operatorname{brl} A$ gene can be induced in submerged liquid culture, either by carbon or nitrogen starvation, or both carbon and nitrogen starvation and that the rate and amount of $\operatorname{brl} A$ mRNA correlates inversely with the morphological complexity of the conidiophore. We propose that $\operatorname{brl} A$ is induced as a response to a general starvation stress condition.

\section{METHODS}

Aspergillus strain and growth conditions. $A$. nidulans strain TJA22 [biA1; brl $A(-2913 p / D) / \operatorname{lacZ}\left(\arg B^{+} / \operatorname{argB}:: C A T\right)$; metG1] (Aguirre, 1993) was grown in appropriately supplemented minimal medium $\left(\mathrm{C}\right.$, glucose $1 \% ; \mathrm{N}, \mathrm{NaNO}_{3}$ or $\mathrm{NH}_{4} \mathrm{Cl}$; Käfer, 1977) at $37^{\circ} \mathrm{C}$ for $18 \mathrm{~h}$ and 300 r.p.m. (culture volume was kept to one-fifth of the flask volume).

Freshly collected 5-d-old spores were filtered through Miracloth (Calbiochem), washed four times with $10 \mathrm{ml}$ sterile water, and used immediately to inoculate a single culture at a density of $5 \times 10^{5}$ conidia $\mathrm{ml}^{-1}$. The inoculated medium was then divided into $50 \mathrm{ml}$ samples per $250 \mathrm{ml}$ Erlenmeyer flask and incubated at $37^{\circ} \mathrm{C}$ for $18 \mathrm{~h}$ and 300 r.p.m. Fresh spores were used because variability in results was observed when using spore suspensions stored at $4{ }^{\circ} \mathrm{C}$ for different times.

For starvation experiments, $50 \mathrm{ml}$ cultures incubated for $18 \mathrm{~h}$ were filtered through Miracloth. Mycelia were briefly rinsed with minimal glucose/nitrate-free medium, and resuspended in $50 \mathrm{ml}$ of either glucose-free or nitrogen-free medium $(250 \mathrm{ml}$ flask) and incubation was continued under the same conditions. For shifts to media with different glucose concentrations or with different carbon sources, filtered cultures were washed with $50 \mathrm{ml}$ pre-warmed sterile water, then with $50 \mathrm{ml}$ supplemented minimal medium with no glucose, and finally resuspended in $50 \mathrm{ml}$ of the appropriate medium. Care was taken to control the amount of biomass transferred to the starvation media, since this can affect both the kinetics and the absolute levels of brl $A /$ lac $Z$ induction.

$\beta$-Galactosidase activity, glucose determination and microscopy. $\beta$-Galactosidase activity was determined as previously reported (Miller, 1972; Aguirre et al., 1990).

Glucose was measured directly from fresh or frozen culture filtrates using a quantitative, enzymic (glucose oxidase) determination kit from Sigma.

Mycelia from different culture conditions were examined under a microscope for conidiophore formation and spore counting, and were photographed using a green filter and Kodak Tri-XPan 400 film.

RNA preparation and analysis. Total mRNA was extracted as described by Timberlake (1980), fractionated by electrophoresis in formaldehyde-agarose gels (10-15 $\mu \mathrm{g}$ per lane), transferred to Hybond-N membranes (Amersham), and hybridized to ${ }^{32} \mathrm{P}-$ labelled random-primed specific probes (BRL) according to the membrane manufacturer's instructions. A brlA Bam HI-EcoRI fragment from pBS2.5 (Boylan et al., 1987) was used as the $\operatorname{brl} A \alpha / \beta$-specific probe, and an $\operatorname{argB} H$ HindIII fragment from pDGH25 (Gems et al., 1991) was used as a probe to confirm equal loading of mRNA samples. For dot-blot analysis, $15 \mu \mathrm{g}$ total mRNA was applied to a Hybond-N membrane as recommended by the manufacturer, and hybridized to ${ }^{32} \mathrm{P}$ labelled random-primed specific probes for $w A$ (SalI-XboI fragment from pNK15; Mayorga \& Timberlake, 1990), y A (XbaI-EcoRI from pRA6; R. Aramayo, unpublished) and $C A N 5$ (Boylan et al., 1987).

\section{RESULTS AND DISCUSSION}

\section{brlA can be induced in submerged cultures by carbon or nitrogen starvation, resulting in different patterns of sporulation}

Martinelli (1976) reported submerged sporulation by $A$. nidulans in liquid cultures using different carbon sources. Since the high surface area/volume ratio $(20 \mathrm{ml}$ medium in $250 \mathrm{ml}$ flasks) used in her experiments could have induced air interface sporulation, we produced submerged sporulation using lower surface area/volume ratios $(50 \mathrm{ml}$ medium in $250 \mathrm{ml}$ flasks), as well as by media shifting, to test the ability of carbon and nitrogen starvation to induce the $\operatorname{br} l A$ gene.

A. nidulans strain TJA22, which contains a single copy of a $b r l A \alpha / \beta$-lac $Z$ gene fusion integrated at the $\arg B$ locus (Aguirre, 1993) was grown in liquid culture for $18 \mathrm{~h}$ at $37^{\circ} \mathrm{C}$ and then the mycelia were shifted to glucose-free medium, nitrate-free medium, or standard medium (Käfer, 1977). Samples were taken at different times and processed for $\beta$-galactosidase assay, mRNA extraction, and microscopic examination. The $\beta$-galactosidase assays showed that both glucose- and nitrate-starvation induced 

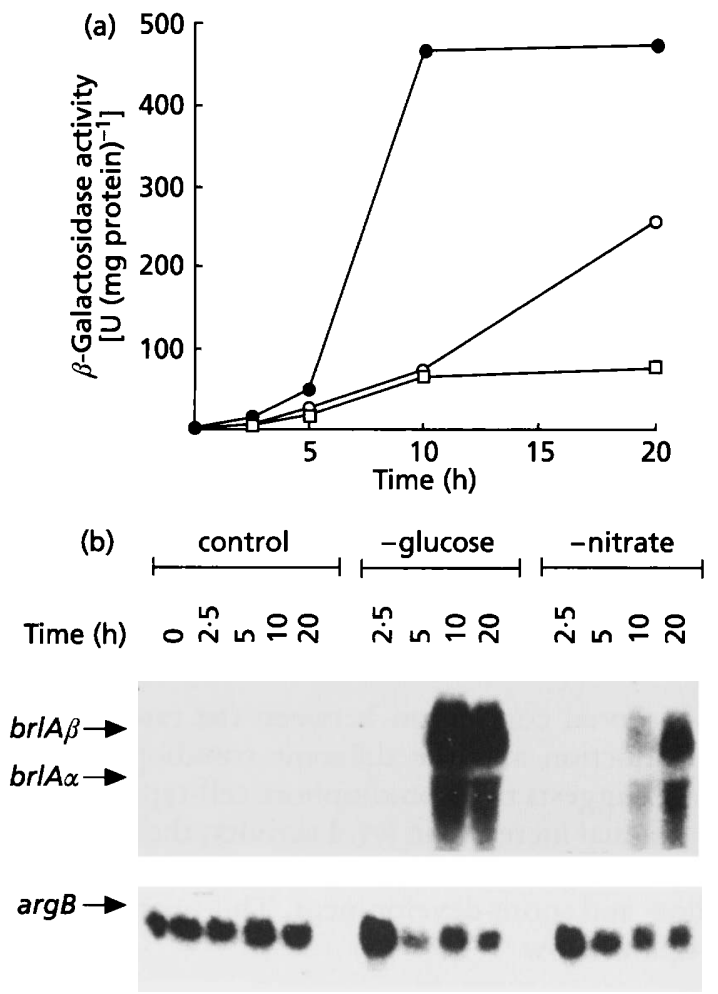

(c)
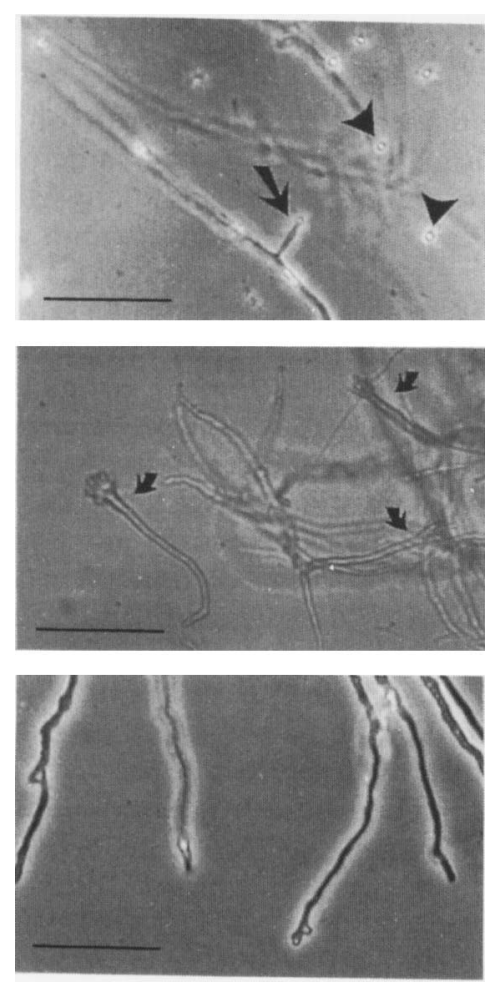

Fig. 1. br/A induction and conidiophore morphology in submerged cultures of $A$. nidulans TJA22 during glucose or nitrate starvation. (a) Accumulation of $\beta$-galactosidase in A. nidulans grown for $18 \mathrm{~h}$ as described in Methods and shifted to media with no glucose (O) or no nitrate $(O)$, or to standard medium $(\square)$ as a control. Incubation was continued under the same conditions and mycelia from entire cultures were harvested at the indicated times, frozen and lyophilized. Part of the samples were processed for $\beta$-galactosidase determination; the $\operatorname{brl} A \alpha / \beta$-lac $Z$ gene; glucose starvation induced $\operatorname{brl} A$ expression more rapidly and to a higher level than nitrate starvation (Fig. 1a). Shifting to standard glucose-nitrate medium caused a slight induction of $\operatorname{brl} A$ at $20 \mathrm{~h}$. Endogenous $\beta$-galactosidase activity was barely detectable in all conditions tested (not shown).

Distinctive morphological changes were observed at $20 \mathrm{~h}$ following shifting to the different media. Glucose starvation induced spore formation from highly reduced conidiophores, bypassing the vesicle and metulae stages (Fig. 1c, top). This morphology was similar to that produced when either $b \operatorname{rl} A \alpha$ or $\operatorname{brl} A \beta$ are induced rapidly to high levels from the inducible alc $A$ promoter (Adams et al., 1988; Han et al., 1993). By contrast, nitrate starvation gave rise to more elaborate conidiophores, similar to those produced at an air interface (Fig. 1c, middle). No obvious signs of sporulation were observed when shifting was to standard medium (Fig. 1c, bottom).

These two different morphological patterns of sporulation may have resulted from differential induction of either $\operatorname{brl} A \alpha$ or $\operatorname{brl} A \beta$ transcripts. To address this question, the presence of both transcripts was assayed by Northern blotting. The results presented in Fig. 1(b) show that both $\operatorname{brl} A \alpha$ and $\operatorname{brl} A \beta \mathrm{mRNAs}$ had accumulated by 10 and $20 \mathrm{~h}$ after shifting to glucose- or nitrate-free medium. Accumulation paralleled $\beta$-galactosidase activity and no clear differences, other than quantitative ones, were observed. In fact, densitometric analysis of Fig. 1(b) showed that the $\operatorname{brl} A \beta / b r l A \alpha$ ratio was around 1.4 in all cases $(b r l A \beta$ is usually more abundant than $\operatorname{brl} A \alpha$; Prade $\&$ Timberlake, 1993). Longer autoradiographic exposure of this Northern blot showed a slight accumulation of $\operatorname{brl} A \mathrm{mRNA}$ when mycelia were transferred to standard $1 \%(\mathrm{w} / \mathrm{v})$ glucose medium, but no obvious morphological changes were detected under those conditions (Fig. 1c, bottom). Other starvation experiments, shifting from glucose$\mathrm{NH}_{4} \mathrm{Cl}$ to glucose-free or $\mathrm{NH}_{4} \mathrm{Cl}$-free media, produced similar results to those shown in Fig. 1(a) and b, i.e. $\operatorname{brl} A /$ lac $Z$ was expressed less when mycelia were nitrogenstarved than when they were glucose-starved, and complex and reduced conidiophores were formed, respectively. Cultures starved of both glucose and nitrate gave results similar to cultures starved of glucose only (some of

specific activity corresponds to $U$ (mg protein) $)^{-1}$ (Miller, 1972). About $300 \mathrm{U}$ is reached $35 \mathrm{~h}$ after induction of sporulation in an air interface (Aguirre, 1993). A representative experiment is shown. (b) br/A $\alpha / \beta$ mRNA accumulation induced by glucose or nitrate starvation. Total mRNA was isolated from samples of the experiment shown in (a), Northern blotted and probed with a $b r I A \alpha / \beta$-specific probe. The lanes correspond to different times after shifting to the indicated media: $0 \mathrm{~h}$ after shifting corresponds to $18 \mathrm{~h}$ growth in standard minimal medium. Equal loading of mRNA was confirmed by stripping the membrane and reprobing with an argB-specific probe. (c) Conidiophore morphology $20 \mathrm{~h}$ after shifting to media with no glucose (top) or no nitrate (middle), or to standard medium (bottom). The long arrow in the top panel indicates a typical reduced conidiophore; arrowheads indicate spores. Short arrows in the middle panel point to complex conidiophores. The bottom panel shows non-differentiated hyphae. Bars, $50 \mu \mathrm{m}$. 
(a)

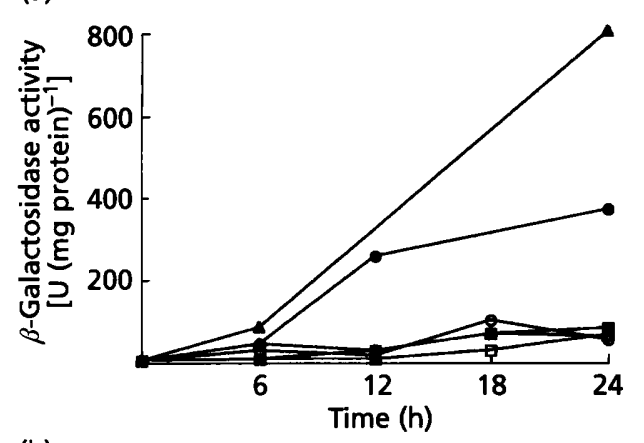

(b)
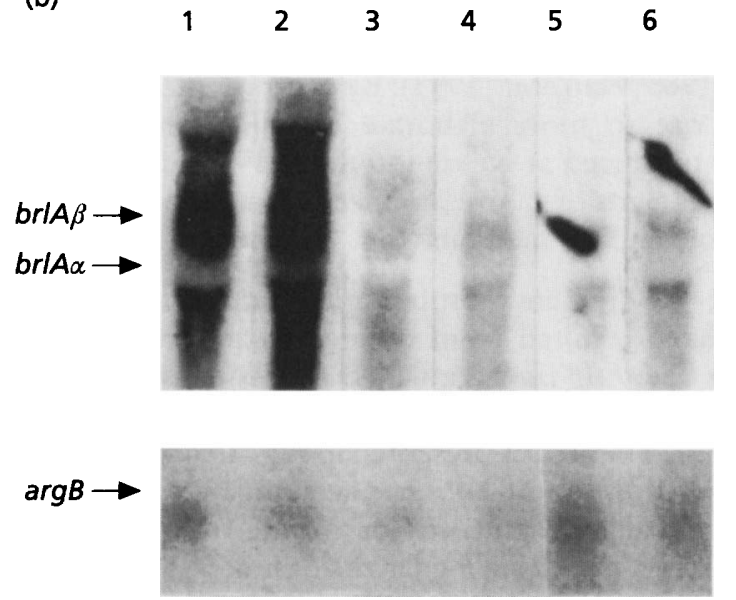

Fig. 2. brlA expression in creA-repressing and non-repressing carbon sources. (a) $A$. nidulans was grown for $18 \mathrm{~h}$ in glucose medium and shifted to media containing either no glucose (O), $0.1 \%$ glucose $(\boldsymbol{A}), 1 \%$ glucose $(\boldsymbol{D}), 1 \%$ arabinose $(0), 1 \%$ glycerol $(\triangle)$ or $100 \mathrm{mM}$ acetate $(\square)$. Samples were isolated at the times indicated and $\beta$-galactosidase was assayed as in Fig. 1. The results represent mean values from two independent experiments with a maximum variation of $16 \%$ about the mean. (b) Total mRNA was isolated from $24 \mathrm{~h}$ samples, Northern blotted and probed with a brlA $\alpha / \beta$-specific probe. Lanes: 1 , no glucose; $2,0.1 \%$ glucose; $3,1 \%$ glucose; $4,1 \%$ arabinose; $5,1 \%$ glycerol; $6,100 \mathrm{mM}$ acetate. Equal loading of mRNA was confirmed by stripping the membrane and reprobing with an argB-specific probe.

these results are shown in Table 2). $b r l A 1$ and $a b a A 2$ null mutants failed to sporulate under these conditions, indicating that submerged sporulation employs the same basic developmental pathway as described previously by Clutterbuck (1969) and Adams et al. (1988). In fact, transcripts from the late sporulation genes $y A, w A$ and CAN5 (Adams et al., 1988; Mayorga \& Timberlake, 1990; Boylan et al., 1987) were detected in 24 h samples starved of glucose. These results are important because in $A$. nidulans, sporulation has been defined as a process triggered not by starvation, but rather by a programmed life-cycle event (Axelrod et al., 1973; Adams et al., 1988, 1992; Mooney \& Yager, 1990; Champe \& Simon, 1992; Han et al., 1993; Lee \& Adams, 1994).

In addition to their relevance for development, we believe that these results have practical consequences for research involving $A$. nidulans as a model system, since it can no longer be assumed that development is prevented by submerged culture conditions. Pertinent to this is the use of the alc $A$ promoter to ectopically express developmental genes (Adams et al., 1988), since this involves growth for $12 \mathrm{~h}$ in glucose and then shifting of mycelia to a poor carbon source such as threonine. As reported by Adams $e t$ al. (1988), we did not find sporulation after $24 \mathrm{~h}$ in threonine medium using our strain TJA22. However, modification of this protocol by growing $18 \mathrm{~h}$ in glucose before shifting gave rise to the formation of complex conidiophores after $24 \mathrm{~h}$ in threonine medium. This implies that care should be taken when modifying the reported protocol (i.e. using ethanol or other inducers instead of threonine, growing for different times before shifting, etc.). In any case, appropriate controls of gene expression have to be included when media manipulations are used to alter the expression of developmental genes.

The observed correlation between the rate and level of $\operatorname{brl} A$ induction and the different conidiophore morphologies, suggests that conidiophore cell-types could result from gradual increases in $b r l A$ activity, the lowest dosage corresponding to vesicle formation and the highest to phialide- and spore-development. This proposal is elaborated upon below.

\section{Non-repressing carbon sources can also prevent brlA accumulation}

To investigate the effect of glucose on $b r l A$ expression, $A$. nidulans TJA22 was grown as before and shifted to media containing glucose $(0,0.1$ or $1.0 \%, \mathrm{w} / \mathrm{v})$, or the cre $A$-mediated non-repressing carbon sources arabinose $(1 \%, w / v)$, glycerol $(1 \%, w / v)$ (Arst \& Bailey, 1977) or acetate $(100 \mathrm{mM})$. Cultures were sampled at different times to determine $\beta$-galactosidase activity and $b r l A$ mRNA accumulation (Fig. 2a, b), morphology (Fig. 3) and spore numbers (Table 1 ). $\beta$-Galactosidase activity was higher when cultures were shifted to $0.1 \%$ glucose than when shifted to glucose-free medium, whereas acetate, arabinose or glycerol were as good as $1 \%$ glucose in preventing $b r l A \alpha / \beta$-lac $Z$ accumulation (Fig. $2 a$ ), allowing a low level of $b r l A$ expression. The $b r l A \alpha / \beta$-lac $Z$ activity also correlated with the actual $\operatorname{br} / A$ mRNA accumulation (Fig. 2b) and, within the limitations of the technique (low brl $A$ transcription is not easily detectable in Northern blots, probably because the $\operatorname{brl} A \mathrm{mRNA}$ is unstable; Prade \& Timberlake, 1993), no obvious difference in the relative abundance of $\operatorname{brl} A \alpha$ or $\operatorname{brl} A \beta$ transcripts was observed between $1 \%$ glucose and the non-repressing carbon sources (Fig. 2b). The high levels of $b r l A$ expression with $0 \cdot 1 \%$ glucose could be related to the fact that this glucose concentration is low enough not to repress $\operatorname{brl} A$, but high enough to fuel the sporulation process. However, glucose was exhausted from the medium by $18 \mathrm{~h}$ after shifting to $1 \%$ glucose (not shown), and the low $\operatorname{brl} A$ induction observed under this condition was probably due to partial carbon starvation.

The results obtained with arabinose, acetate and glycerol make it unlikely that $\operatorname{brl} A$ glucose repression could be directly mediated by a cre $A$-dependent carbon catabolite 

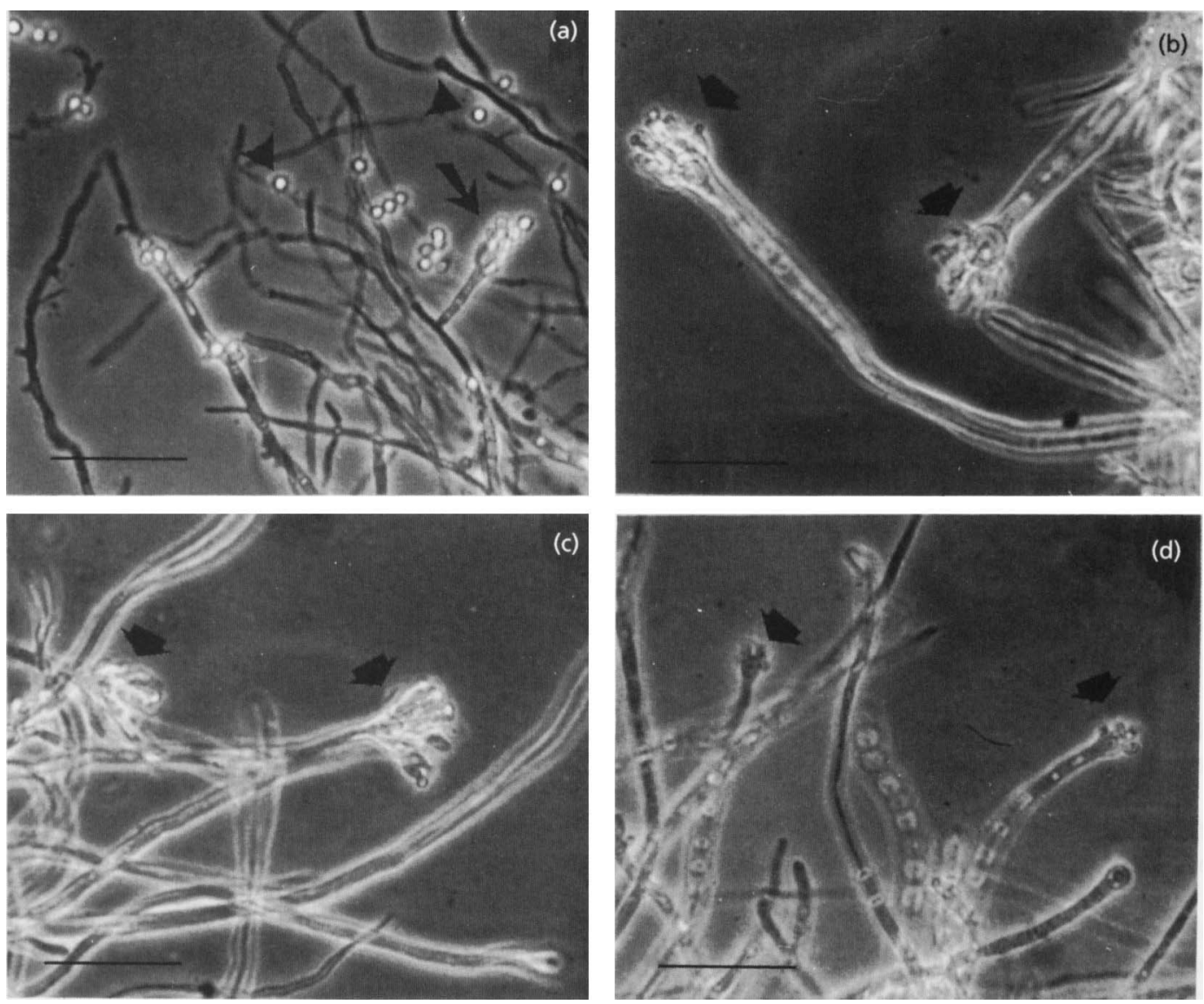

Fig. 3. Conidiophore morphologies $24 \mathrm{~h}$ after shifting of glucose-nitrate grown mycelia to different carbon sources: (a), $0.1 \%$ glucose; (b), $1.0 \%$ arabinose; (c), $1.0 \%$ glycerol; and (d), $100 \mathrm{mM}$ acetate. The long arrow in (a) indicates a reduced conidiophore and arrowheads indicate spores. The thick arrows in (b)-(d) indicate complex conidiophores. Bars, $20 \mu \mathrm{m}$.

repression mechanism (Arst \& Bailey, 1977; Dowzer \& Kelly, 1991). Instead, we propose that $\operatorname{brl} A$ is regulated by nutrient limitation and that starvation for carbon, nitrogen, carbon and nitrogen, or other nutrients can lead to a similar kind of metabolic stress (see Hansberg \& Aguirre, 1990).

\section{Rate and level of brlA expression correlates with the complexity of conidiophore development}

Figure 3 shows the morphology observed in some of the $24 \mathrm{~h}$ samples exposed to different carbon sources from the experiment presented in Fig. 2. Again, rapidly increasing levels of $\beta$-galactosidase activity and $\operatorname{brl} A$ mRNA corresponded with high spore numbers and reduced conidiophore morphology (Fig. 1c, top, Fig. 3a, and Table 1), whereas low but gradually increasing levels corresponded with either the absence of sporulating structures (as in Fig. 1c, bottom), or the presence of few conidiophores with more complex morphology and low spore production (Fig. 3b-d; Table 1). As in the experiments shown in Fig. 1, these different conidiophore morphologies could not be correlated with differential expression of either $\operatorname{brl} A \alpha$ or $b r l A \beta$ transcripts, as judged from
Northern blots (Fig. 2b). These results support a quantitative model for $b r l A$ regulation of conidiophore development, which would be consistent with the following findings. Firstly, high induction of either of the two $\operatorname{brl} A$ transcripts $(\alpha$ or $\beta$ ) from the strongly inducible alc $A$ promoter causes spore production directly from hyphal tips (Adams et al., 1988; Han et al., 1993), a morphology virtually identical to that observed in the glucose starvation experiments (Figs 1c and 3a). Secondly, $b r l A \alpha$ and $b r l A \beta$ seem to perform similar functions, since multiple copies of either $b r l A \alpha$ or $b r l A \beta$ can overcome the need for the other transcript during normal development (Prade \& Timberlake, 1993). Thirdly, developmental mutants such as med $A$ and stu $A$ (Clutterbuck, 1969; Miller et al., 1992) present aberrant conidiophore morphologies that are consistent with their abnormal temporal or spatial transcription of $b r l A$ (Aguirre, 1993).

Several cis-acting regulatory elements could regulate $b r l A$ transcription rates through multiple inputs such as carbon and nitrogen starvation. It is important to note that $\operatorname{brl} A$ regulatory sequences, up to $-2913 \mathrm{bp}$, are required for full $b r l A$ expression, and progressive deletion of these sequences in a $\operatorname{brl} A \alpha / \beta$-lac $Z$ fusion gradually decreases 
Table 1. Spore production and external $\mathrm{pH}$ after shifting to different carbon sources

Mycelia grown in minimal nitrate-glucose $(1 \%)$ media for $18 \mathrm{~h}$ were shifted to the indicated carbon sources and sampled for spore production after $24 \mathrm{~h}$ and for external $\mathrm{pH}$ after 6 and $24 \mathrm{~h}$. Spore numbers shown are mean values from duplicates with a maximum variation of $13 \%$ about the mean.

\begin{tabular}{|lrrr|}
\hline \multirow{2}{*}{$\begin{array}{l}\text { Minimal } \\
\text { medium } \\
\text { plus: }\end{array}$} & $\begin{array}{c}\mathbf{1 0}^{\mathbf{- 3}} \times \text { Spores } \\
\text { per culture }\end{array}$ & \multicolumn{2}{l|}{ External $\mathbf{~} \mathbf{H}$} \\
\cline { 3 - 4 } & & $\mathbf{6 ~ h}$ & $\mathbf{2 4} \mathbf{~ h}$ \\
\hline No glucose & 50000 & $6 \cdot 8$ & $7 \cdot 2$ \\
$0 \cdot 1 \%$ glucose & 130000 & $7 \cdot 1$ & $7 \cdot 6$ \\
$1 \%$ glucose & 8 & $7 \cdot 6$ & $8 \cdot 4$ \\
$1 \%$ arabinose & 20 & $7 \cdot 5$ & $8 \cdot 3$ \\
$1 \%$ glycerol & 14 & 6.9 & $8 \cdot 1$ \\
100 mM acetate & 14 & 8.5 & 8.8 \\
\hline
\end{tabular}

maximum $\beta$-galactosidase levels but does not alter the developmental timing or cellular specificity of expression (J. Aguirre \& W. E. Timberlake, unpublished). Miller (1993) has pointed out that several $b r l A$-dependent genes contain more than one copy of $b r l A$-responsive elements (Chang \& Timberlake, 1992), providing a mechanism for a $\operatorname{brl} A$ dosage control of development. In microorganisms, incremental regulation of gene expression has been shown for the Myxococcus xantus csg $A$ gene, which encodes an extracellular protein whose steady increases are regulated at the transcriptional level and determine the proper ordering of developmental steps ( $\mathrm{Li}$ et al., 1992).

We cannot explain why some conidiophore development occurs in non-repressing carbon sources (Fig. 3b-d), but it does not occur in $1 \%$ glucose (Fig. 1c), despite similar moderate levels of $b r l A$ expression being detected in all these conditions. It is possible that although $\operatorname{brl} A$ itself does not seem to be repressed by glucose through a cre $A$ dependent mechanism, other genes necessary for sporulation could be repressed by the glucose-cre $A$ system. The different carbon sources could also have diverse effects on $\operatorname{brl} A$ at the translational level (i.e. by stabilizing the $\operatorname{br} l A$ messages), since there is evidence showing that $\operatorname{brl} A \beta$, but not $\operatorname{brl} A \alpha$, is regulated by translational repression (Han $e t$ al., 1993). Further work is necessary to answer these questions.

\section{pH changes during starvation-induced brlA expression}

Espeso et al. (1993) have shown that the ipn $A$ gene, which encodes isopenicillin $N$-synthase, is carbon repressed by a cre $A$-independent mechanism that can be overcome by external alkaline $\mathrm{pH}$. We monitored $\mathrm{pH}$ changes during growth and liquid sporulation in different carbon sources. The $\mathrm{pH}$ values in Table 1 show that incubation in the different carbon sources resulted in different degrees of medium alkalinization. The largest differences occurred during the first $6 \mathrm{~h}$ of incubation, and acetate and $1 \%$
Table 2. Spore production, conidiophore morphology and external $\mathrm{pH}$ changes induced by different types of starvation

Experimental conditions were as indicated for Table 1, except that shifting was to media lacking either glucose, nitrate or ammonium, or both glucose and nitrate. When shifting was to media with or without ammonium, the $18 \mathrm{~h}$ pre-growth was done in glucose-ammonium medium. Spore production and conidiophore morphology were determined on $24 \mathrm{~h}$ samples. $\mathrm{pH}$ was determined in medium samples from 6 and $24 \mathrm{~h}$. Representative results are shown.

\begin{tabular}{|c|c|c|c|c|}
\hline \multirow{2}{*}{$\begin{array}{l}\text { Type of } \\
\text { starvation }\end{array}$} & \multirow{2}{*}{$\begin{array}{c}10^{-3} \times \text { Spores } \\
\text { per culture }\end{array}$} & \multirow{2}{*}{$\begin{array}{l}\text { Conidiophore } \\
\text { morphology }\end{array}$} & \multicolumn{2}{|c|}{ External pH } \\
\hline & & & $6 \mathrm{~h}$ & $24 \mathrm{~h}$ \\
\hline $\begin{array}{l}\text { - Glucose } \\
\text { + Nitrate }\end{array}$ & 50000 & Reduced & $6 \cdot 8$ & $7 \cdot 2$ \\
\hline $\begin{array}{l}\text { - Glucose } \\
+ \text { Ammonium }\end{array}$ & 3100 & Reduced & $6 \cdot 0$ & $6 \cdot 2$ \\
\hline $\begin{array}{l}\text { + Glucose } \\
\text { - Nitrate }\end{array}$ & 64900 & Complex & $6 \cdot 2$ & $6 \cdot 1$ \\
\hline $\begin{array}{l}\text { + Glucose } \\
\text { - Ammonium }\end{array}$ & 52800 & Complex & $6 \cdot 3$ & $6 \cdot 2$ \\
\hline $\begin{array}{l}\text { - Glucose } \\
\text { - Nitrate }\end{array}$ & 107000 & Reduced & 6.5 & $6 \cdot 8$ \\
\hline
\end{tabular}

glucose resulted in the strongest alkalinization after $24 \mathrm{~h}$. When mycelia were shifted to $1 \%$ glucose containing $\mathrm{NH}_{4} \mathrm{Cl}$ rather than $\mathrm{NaNO}_{3}, b r l A$ was fully repressed and, in this case, external $\mathrm{pH}$ became acidic instead of alkaline (not shown), indicating that glucose prevented $b r l A$ expression in both alkaline and acidic conditions.

These results argue against external $\mathrm{pH}$ changes as the sole explanation for the different morphologies observed in repressing and non-repressing carbon sources. However, we observed that submerged sporulation induced either by starvation of glucose, nitrate, ammonium, or by simultaneous glucose and nitrate starvation, always resulted in external $\mathrm{pH}$ values close to neutrality (Table $2)$; in fact, sporulation was reduced, but not prevented, when mycelia were starved of both glucose and nitrate in medium previously adjusted to $\mathrm{pH} 4$ or 8 .

\section{Without media shifting, submerged sporulation does not occur, even after glucose exhaustion}

All the experiments reported above were done by growing mycelia for $18 \mathrm{~h}$ in standard minimal nitrate-glucose medium (Käfer, 1977), and then transferring to different media. The same kind of experiment was performed without media shifting and the resulting culture was sampled at different times. It was found that external $\mathrm{pH}$ became strongly alkaline and $\mathrm{br} / \mathrm{A} / \mathrm{lac} Z$ was induced to moderate levels after glucose was exhausted (Fig. 4a). However, no signs of sporulation were observed even after prolonged incubation (morphology was similar to that shown in Fig. 1c; bottom). Most of the reluctance to 
(a)

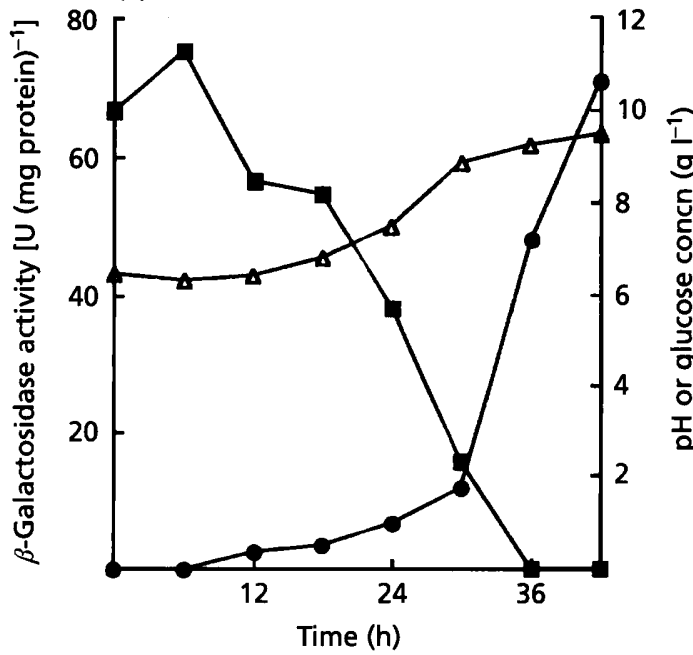

(b)

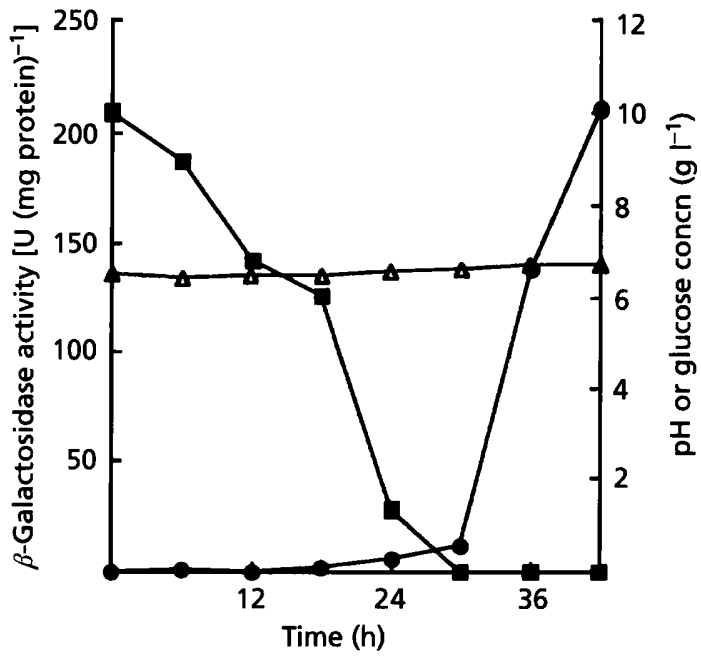

Fig. 4. br/A/lacZ induction (O), glucose consumption ( $\square$ ) and external $\mathrm{pH}(\triangle)$ during growth of $A$. nidulans in minimal nitrate-glucose liquid medium without (a) or with (b) $0.1 \mathrm{M}$ sodium phosphate buffer. Minimal nitrate-glucose (1\%) medium with or without buffer was inoculated with $A$. nidulans and grown for $42 \mathrm{~h}$. At the indicated times, mycelial samples were harvested and assayed for $\beta$-galactosidase. Medium samples were used for glucose and $\mathrm{pH}$ determinations (Methods). A representative experiment is shown.

consider submerged sporulation as a common occurrence, and starvation as a triggering factor, could be related to this finding, since Käfer's medium is used extensively.

Considering that the buffering capacity of Käfer's medium is very limited ( $\left.11 \mathrm{mM} \mathrm{KH}_{2} \mathrm{PO}_{4}\right)$, and that our previous results suggested that strong deviation from external neutral $\mathrm{pH}$ could partially prevent full induction and/or function of $b r l A$, we decided to include $0.1 \mathrm{M}$ sodium phosphate buffer in Käfer's medium and follow external $\mathrm{pH}, \quad b r / A / l a c Z$ induction and morphological changes during growth. Fig. 4(b) shows that external $\mathrm{pH}$ was maintained around 6.5 and that $b r l A / l a c Z$ was induced to higher levels $(\approx 200 \mathrm{U})$ than those shown in Fig. 4(a) $(\approx 70 \mathrm{U})$. Abundant sporulation (complex conidiophores) was observed under these conditions by $42 \mathrm{~h}$, showing that reproducible submerged sporulation can be obtained in standard buffered media without media shifting. Even in this case, starvation (glucose exhaustion) seems to be a necessary step. It should be noted that previously reported submerged sporulation was observed in media that included 0.1 M phosphate buffer (Martinelli, 1976).

\section{Concluding remarks}

The results presented in this paper show that the $\operatorname{brl} A$ gene and sporulation can be induced under defined liquid culture conditions by different environmental stimuli. This could be an important tool to study the signals that initiate development in $A$. nidulans. Further studies are needed to elucidate the molecular mechanisms by which nutrient starvation induces $\operatorname{brl} A$ and how this is affected by external $\mathrm{pH}$. Particularly relevant to this understanding would be the study of starvation effects on genes known to affect $\operatorname{brl} A$ expression, such as $\operatorname{stu} A$ and $\operatorname{med} A$ (Clutterbuck, 1969; Miller, 1993; Aguirre, 1993), as well as the roles that the carbon and nitrogen catabolite regulator genes $\operatorname{cre} A$ and are $A$ (Arst \& Bailey, 1977; Kudla et al., 1990) could have in this process. Developmental competence (Axelrod et al., 1973) is necessary for air-interface-induced conidiation. Thus, it is relevant to address the question of whether or not competence is required for nutrient stress induced sporulation, and we are currently working on this.

\section{ACKNOWLEDGEMENTS}

We thank Paula González for experimental support and Dr Rodolfo Aramayo for helpful discussion. We also thank Drs Wilhelm Hansberg, Joan Kelly and Ralph Dean for critical reading of the manuscript. This work was supported by grants 0708-N9109 from CONACyT, Mexico, and IN200192 from DGAPA-UNAM, Mexico.

\section{REFERENCES}

Adams, T. H., Boylan, M. T. \& Timberlake, W. E. (1988). $b r l A$ is necessary and sufficient to direct conidiophore development in Aspergillus nidulans. Cell 54, 353-362.

Aguirre, J. (1993). Spatial and temporal controls of the Aspergillus brl $A$ developmental regulatory gene. Mol Microbiol 8, 211-218.

Aguirre, J., Adams, T. H. \& Timberlake, W. E. (1990). Spatial control of developmental regulatory genes in Aspergillus nidulans. Exp Mycol 14, 290-293.

Arst, H. N. \& Bailey, C. R. (1977). The regulation of carbon metabolism in Aspergillus nidulans. In Genetics and Pbysiology of Aspergillus, pp. 131-146. Edited by J. A. Pateman \& J. E. Smith. New York: Academic Press.

Axelrod, D. E., Gealt, M. \& Pastushok, M. (1973). Gene control of developmental competence in Aspergillus nidulans. Dev Biol 34, 9-15.

Boylan, M. T., Mirabito, P. M., Willett, C. E., Zimmerman, C. R. \& Timberlake, W. E. (1987). Isolation and physical characterization of three essential conidiation genes from Aspergillus nidulans. Mol Cell Biol 7, 3113-3118. 
Champe, S. P. \& Simon, L. D. (1992). Cellular differentiation and tissue formation in the fungus Aspergillus nidulans. In Morphogenesis: an Analysis of the Development of Biological Structures, pp. 63-91. Edited by E. Rossomando \& S. Alexander. New York: Marcel Dekker.

Chang, Y. C. \& Timberlake, W. E. (1992). Identification of Aspergillus brl $A$ response elements (BREs) by genetic selection in yeast. Genetics 133, 29-38.

Clutterbuck, A. J. (1969). A mutational analysis of conidial development in Aspergillus nidulans. Genetics 63, 317-327.

Clutterbuck, A. J. (1990). The genetics of conidiophore pigmentation in Aspergillus nidulans. J Gen Microbiol 136, 1731-1738.

Dowzer, C. E. A. \& Kelly, J. M. (1991). Analysis of cre $A$ gene, a regulator of carbon catabolite repression in Aspergillus nidulans. Mol Cell Biol 11, 5701-5709.

Espeso, E. A., Tilburn, J., Arst, H. N. \& Peñalva, M. A. (1993). pH regulation is a major determinant in expression of a fungal penicillin biosynthetic gene. EMBO J 12, 3947-3956.

Gems, D., Johnstone, I. \& Clutterbuck, A. J. (1991). An autonomously replicating plasmid transforms $A$ spergillus nidulans at high frequency. Gene 98, 61-67.

Han, S., Navarro, J., Greve, R. A. \& Adams, T. H. (1993). Translational repression of $\mathrm{brl} A$ expression prevents premature development in Aspergillus. EMBO J 12, 2449-2457.

Hansberg, W. \& Aguirre, J. (1990). Hyperoxidant states cause microbial cell differentiation by cell isolation from dioxygen. $J$ Theor Biol 142, 201-221.

Kafer, E. (1977). Meiotic and mitotic recombination in Aspergillus and its chromosomal aberrations. Adv Genet 19, 33-131.

Kudla, B., Caddick, M. X., Langdon, T., Martinez-Rossi, N. C., Bennet, C. F., Sibley, S., Davies, R. W. \& Arst, H. N., Jr (1990). The regulatory gene are $A$ mediating nitrogen metabolite repression in Aspergillus nidulans. Mutations affecting specificity of gene activation alter a loop residue of a putative Zinc finger. EMBO J 9, 1355-1364.

Lee, B. N. \& Adams, T. H. (1994). The Aspergillus nidulans fu $G$ gene is required for production of an extracellular developmental signal and is related to prokaryotic glutamine synthetase I. Genes \& Dev 8, 641-651.

Li, S., Lee, B. \& Shimkets, J. (1992). $\operatorname{csg} A$ expression entrains Myxococcus xanthus development. Genes \& Dev 6, 401-410.

Martinelli, S. D. (1976). Conidiation of Aspergillus nidulans in submerged culture. Trans Br Mycol Soc 67, 121-128.
Mayorga, M. E. \& Timberlake, W. E. (1990). Isolation and molecular characterization of the Aspergillus nidulans $w A$ gene. Genetics 126, 73-79.

Miller, B. L. (1993). Brushing up on bristles: complex genes and morphogenesis in molds. Trends Genet 9, 293-295.

Miller, J. H. (1972). Experiments in Molecular Genetics. Cold Spring Harbor, NY: Cold Spring Harbor Laboratory.

Miller, K. Y., Wu, J. G. \& Miller, B. L. (1992). StuA is required for cell pattern formation in Aspergillus. Genes \& Dev 6, 1770-1782.

Mims, C. W., Richardson, E. A. \& Timberlake, W. E. (1988). Ultrastructural analysis of conidiophore development in the fungus Aspergillus nidulans using freeze substitution. Protoplasma 144, 132-141.

Mirabito, P. M., Adams, T. H. \& Timberlake, W. E. (1989). Interactions of three sequentially expressed genes control temporal and spatial specificity in Aspergillus development. Cell 57, 859-868.

Mooney, J. L. \& Yager, L. N. (1990). Light is required for conidiation in Aspergillus nidulans. Genes \& Dev 4, 1473-1482.

Oliver, P. T. P. (1972). Conidiophore and spore development in Aspergillus nidulans. J Gen Microbiol 73, 45-54.

Prade, R. A. \& Timberlake, W. E. (1993). The Aspergillus nidulans brl $A$ regulatory locus consists of overlapping transcription units that are individually required for conidiophore development. EMBO J 12, 2439-2447.

Strauch, M. A. \& Hoch, J. A. (1992). Sporulation in prokaryotes and lower eukaryotes. Curr Opin Genet Dev 2, 799-804.

Stringer, M. A., Dean, R. W., Sewall, T. C. \& Timberlake, W. E. (1991). Rodletless, a new Aspergillus developmental mutant induced by direct gene inactivation. Genes \& Dev 5, 1161-1171.

Timberlake, W. E. (1980). Developmental gene regulation in Aspergillus nidulans. Dev Biol 78, 497-510.

Timberlake, W. E. (1991). Temporal and spatial controls of Aspergillus development. Curr Opin Genet Dev 1, 351-357.

Zimmermann, C. R., Orr, W. C., Leclerc, R. F., Barnard, E. C. \& Timberlake, W. E. (1980). Molecular cloning and selection of genes regulated in Aspergillus development. Cell 21, 709-715.

Received 15 June 1994; revised 6 September 1994; accepted 23 September 1994. 